\title{
MicroscopyPioneers
}

\section{Grace Burke: Show Me the Data}

\section{Cameron Varano}

The Pennsylvania State University, 201 Old Main, University Park, PA 16802

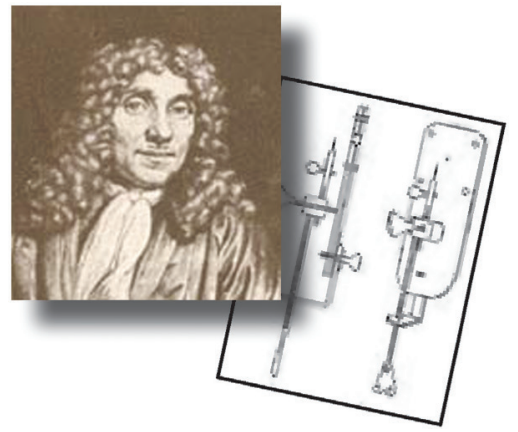

cvarano@psu.edu

I remember the first time I met Dr. Mary Grace Burke in 2017 at Microscopy and Microanalysis in St. Louis. It was over a gin and tonic with a sprig of rosemary per her recommendation. Within moments into the conversation I, along with others at the table, was filled with her infectious enthusiasm despite the late hour. Grace exudes that rare form of genuine zeal that while excited is also discerning. As the discussion ping-ponged from one matter of microscopy to another, Burke remained enthralled by scien-

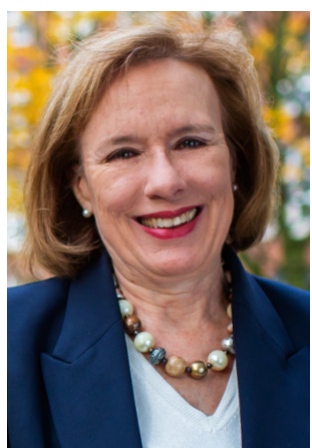

Grace Burke tific conversation even as it drifted from her own field of study. I also discovered she carries a bag that most humans would require a forklift to move.

These are not profound insights into who Dr. Grace Burke is. Sitting down to formally interview her I realized that Burke is not a self-promoter-not even when asked directly to do so. I have the recording to prove it. It takes less than two complete sentences for Burke to redirect the conversation away from herself. I don't think this is due to a bashful personality. It may be from years spent in industry where the emphasis is put on outcomes rather than promoting individual thinkers. Though I believe it is because to her, there are much more interesting subject matters than herself. Well, Grace, I respectfully disagree. Dr. Grace Burke is a scientist who has seamlessly worked within industry and academia and has served on government panels. Her work is purpose-driven and held to Burke's personal standard of rigor that few can match. She has served as President for both the Microscopy Society of America and the Royal Microscopy Society. She does it all with her hallmark energy.

She was raised in Pittsburgh, Pennsylvania and attended the University of

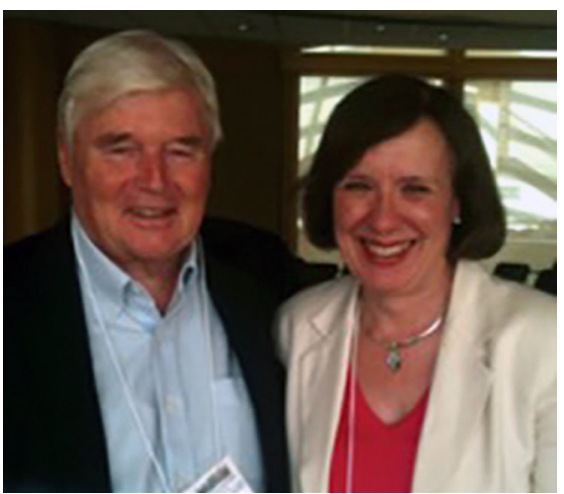

Peter Swann and Grace Burke
Pittsburgh for her undergraduate studies in Metallurgical Engineering. After graduating she traveled across the Atlantic to the Imperial College of Science and Technology in London where she became a postgrad (the British equivalent to a graduate student). Grace joked as she translated that she is bilingual-knowing both British and American English. She was offered a PhD studentship by Peter Swann to research mechanisms of stress corrosion cracking of austenitic stainless steel for her graduate studies. However, after a few months, Peter left London for Pittsburgh/Warrendale to build Gatan. Although Peter visited a few times a year, it was F. J. (John) Humphreys who took Grace under his wing. His work was focused on recrystallization of alloys rather than stress corrosion cracking (SCC), and, consequently, she had a higher-level autonomy with her research. John Humphreys' "hands-on" approach to his own research (typical of the other Imperial EM academics, Harvey Flower and E. Paul Butler) made an impression on young Grace, who was the only "foreigner" in the group. This "hands-on" approach is a trait Burke herself has carried throughout her career.

During her days as a graduate student, she was focused on identifying and understanding the mechanism of SCC, including the role of alloy microstructure in the degradation phenomenon. To fully explore SCC she employed TEM and a new technique, STEM-EDX microanalysis, as well as SEM on a JEOL 120CX TEMSCAN. While most days she could be found in the sub-sub-basement on a TEM, S/STEM, or HVEM, she saw herself as a metallurgist using microscopy to understand materials behavior rather than as a microscopist. This identity shifted a bit when she began working for US Steel at their Monroeville, Pennsylvania Research Laboratory. US Steel was her first position after obtaining her $\mathrm{PhD}$, which she obtained two weeks before she married Mike Burke. Notably, she was the first female PhD hired at the Research Laboratory. When she arrived at US Steel there were two JEOL TEMSCANs being 


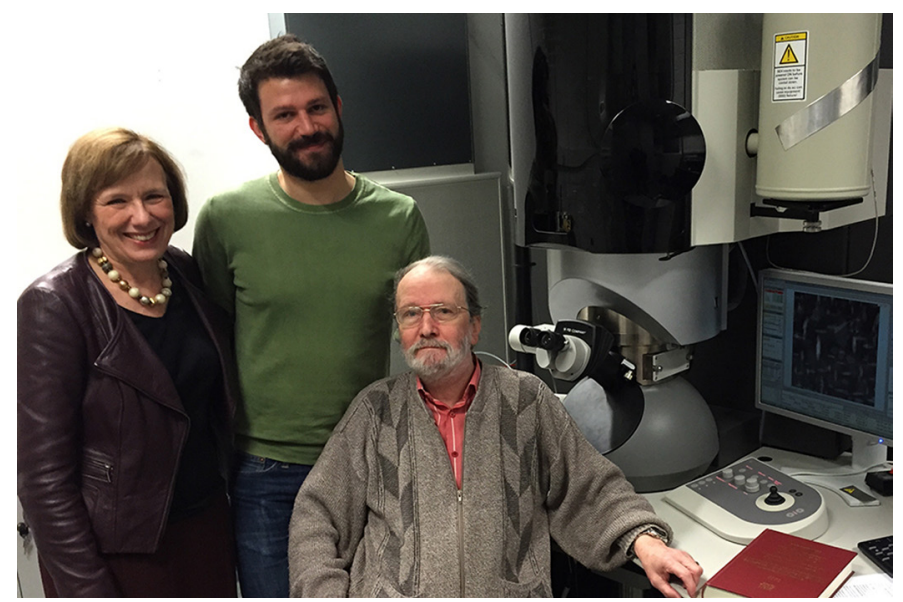

Grace Burke, Giacomo Bertali (PhD student,) and Graham Cliff (of Cliff-Lorimer) with the University of Manchester FEI Titan.

installed but no users, so she became a primary user of those analytical electron microscopes (AEMs) to study recrystallization of steels, carbide precipitation, dual-phase steels, and some cool Fe-Be alloys. Serendipitously, just down the hall from Burke one of the same steel samples was being characterized by Sid Brenner and Mike Miller using atom probe field ion microscopy (APFIM). When the two groups compared data, they found that the bimodal distribution of the two techniques overlapped at the finest point of the TEM data and the coarsest point of the atom probe analysis. They linked the data sets and eventually published the findings in Metal Science. Equally important to Burke, she learned the fascinating and very challenging technique of APFIM, expanding not only her technique repertoire but also her scientific network. The connections made at US Steel would eventually serve to connect her to Oak Ridge National Laboratory (Mike Miller, Jim Bentley, Ed Kenik) for collaborations on later studies. While at US Steel, Grace started research with Brenner on irradiation embrittlement of reactor pressure vessel steels, thanks to a metallurgist from Carolina Power and Light Company, Sam Grant, who discovered the problem 15 years earlier. Grace continued to focus on irradiation damage in neutron irradiated reactor pressure vessel steels to detect the "invisible" irradiation features that were responsible for the embrittlement during her time on the Research Faculty at the University of Pittsburgh after the demise of US Steel's Research Laboratory. However, the real challenge was collecting sufficient data in a volume and manner to give credence to the APFIM, as data collection was extremely time-consuming and required many specimens. In the mid-1980s, the scientific community was quite hesitant to accept data concerning nanoscale solute clustering collected using APFIM. This led to many further metallurgical studies applying both AEM and APFIM to provide comprehensive complementary data for detailed microstructural characterization. Though, perhaps, the most difficult person to convince was Burke herself. She is careful to distinguish findings into indicative data and conclusive data.

Grace joined the Westinghouse Science and Technology Center in 1987, where she continued her research involving

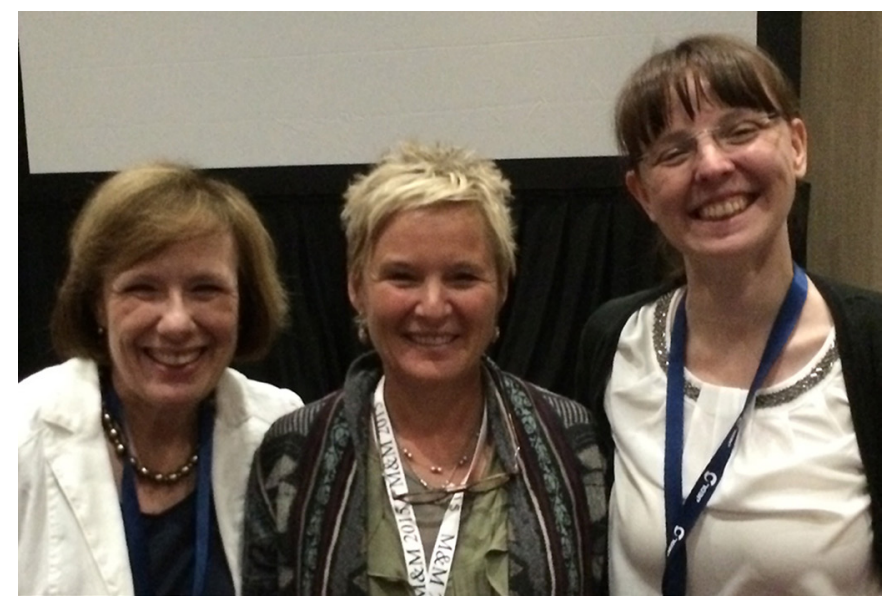

Grace Burke, Karin Swann, and Sibylle Schilling (M\&M Awardee) at PR Swann Memorial Symposium on In Situ Microscopy at M\&M 2015.

materials for nuclear power systems, as well as working with colleagues on semiconductors and novel materials. Interestingly, Burke's father also worked at Westinghouse as a mechanical engineer for nearly 48 years, as did her grandmother around 1920. Although, her grandmother was required to give up her work as a secretary once she became engaged, a requirement that fortunately became illegal with the Civil Rights Act of 1964. Burke transferred to the Bettis Laboratory, a Westinghouse division, after the birth of her daughter, Eileen. Grace continued in her microstructurally oriented research focusing on the relationship between microstructure and material performance, though her title changed from Fellow Scientist to Advisory Scientist to Consultant Scientist. She became the first woman Consultant at the Laboratory.

In 2011, she accepted a position at the University of Manchester as Professor and Director of the Materials Performance Centre, and within six months was also asked to be Director of the Electron Microscopy Centre, which she led through 2016. Despite the responsibility that comes with the positions, she still finds time to spend on the instruments. She wholeheartedly enjoys the opportunities to work with grad students to share her knowledge and expertise, and stresses attention to detail in research. Her courses are lauded by students in part due to her experience in industry, but mostly because they, like me, are affected by her infectious enthusiasm.

Her early work using APFIM was not the only time in her career Burke was an earlier adopter. When asked about her contribution of in situ TEM, she was quick to remind me that it was not a new technique. The technique was used by Peter Swann and others in the 1970s with the $1 \mathrm{MeV}$ highvoltage electron microscopes. Perhaps, it was more accurate to say that Burke helped usher the technique into the current age of applied in situ microscopy. Speaking with her colleagues, they agree she is an early adopter, but always a skeptical adopter. Willing to try a technique, but not willing to casually give credence. She needs to see the data along with complementary supporting data. A natural consequence of this meticulous approach is the high respect gained by colleagues. Every person I spoke to about Burke's work used the 
word "rigorous." Dr. Nestor Zaluzec remarked that there is no one more difficult to convince of her own data than Grace Burke. A trait that we all strive for, but few have the patience to fully carry through.

Burke is currently the 2019-2022 President of the Royal Microscopy Society. As President she and her RMS colleagues have been encouraging and creating space for the young members of the Society and reinvigorating RMSMSA travel awards for student/early career members. Inclusivity seems to be a hallmark of her leadership platform. In 2005, as President of the Microscopy Society of America, she worked to further the involvement of biological sciences in the society. She is the only person to have served as President for both societies. Additionally, as Bev Maleeff relates of her own and others' experience, Grace has been a valued mentor and coach for junior colleagues as they progress into leadership roles in MSA.

Burke is looking ahead to the next big questions in environmentally sensitive behavior of materials driven by the extension of nuclear operation licenses as well as the needs for advanced nuclear power systems. She has carried her results-oriented perspective from industry to academia. While she is conducting research at the nano level, she keeps in mind its relevance to bulk property data. When asked if she could have one wish granted in the field of science, it was time. Time to write many papers and catch up on $\sim 7000$ unread emails.

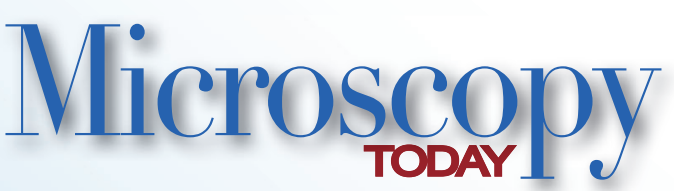

Micrograph Awards
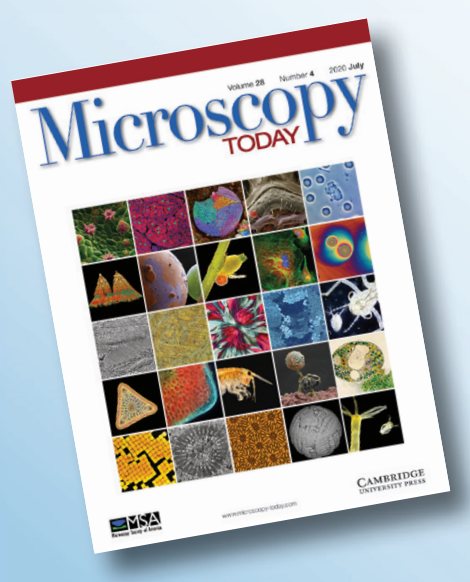

The July 2020

issue featuring the 2020 finalists and information about the competition

To submit your micrograph go to: https://www.microscopy.org/awards/ micrograph_competition.cfm

Next deadline: February 22, 2021
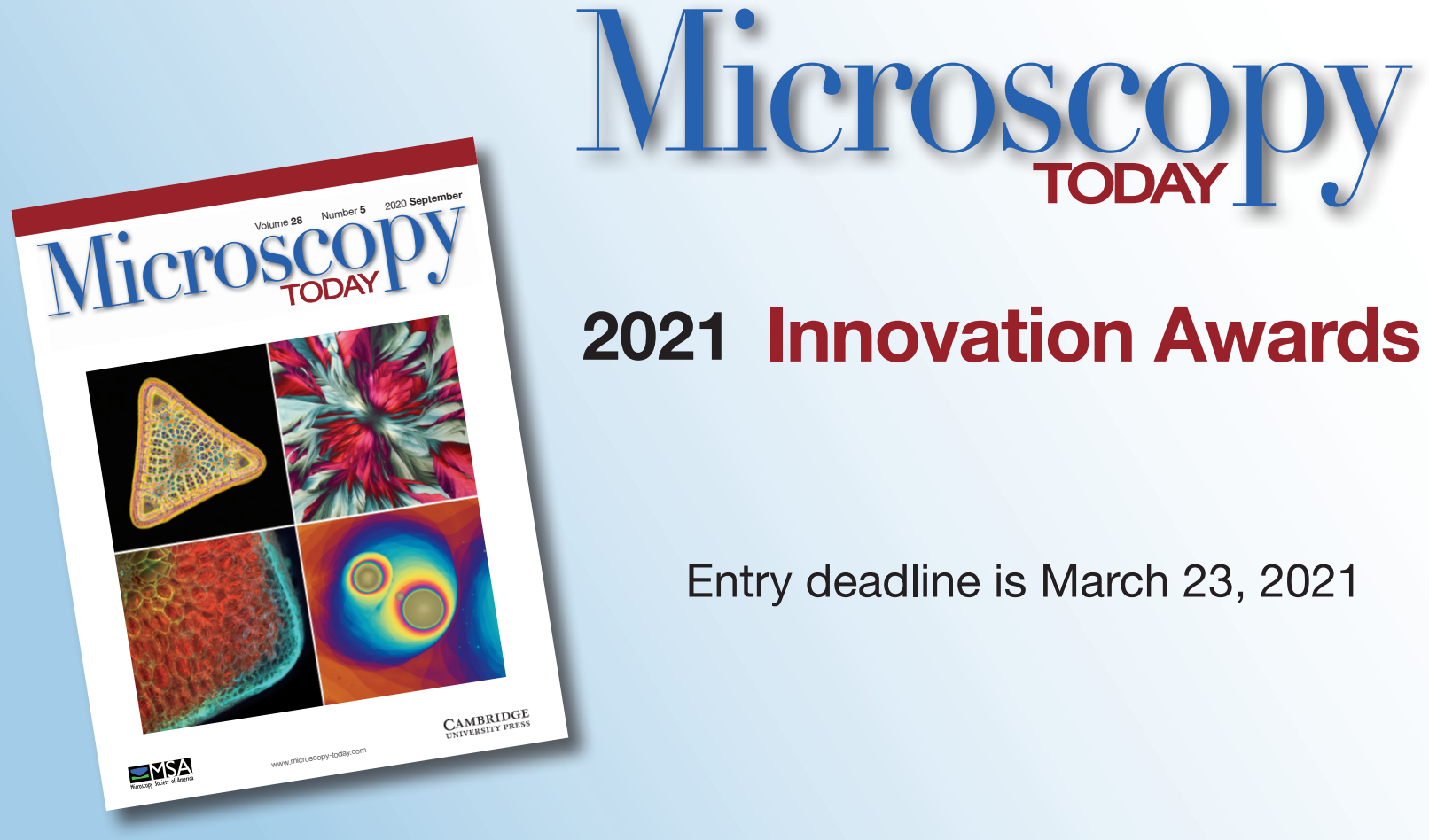

\title{
2021 Innovation Awards
}

\author{
Entry deadline is March 23, 2021
}

Request application forms by email: charles.lyman@lehigh.edu 


\section{TGS Technologies, LLC}

\section{TEM Sample Holder Service and Modification Specialist}

With over 40 years of experience repairing TEM Sample Holders, we provide you with high-quality personalized service. We specialize in repair, modification, and refurbishment of your sample holder as well as custom design if you are seeking specific innovative needs from your equipment.

TGS Technologies, LLC Ph: 724-453-3865

Fx: 724-453-2968

Email: tom@tgstechnologies.net http://www.tgstechnologies.net

\section{D Mreromac}

microPREPTM PRO

High-Speed Sample Preparation

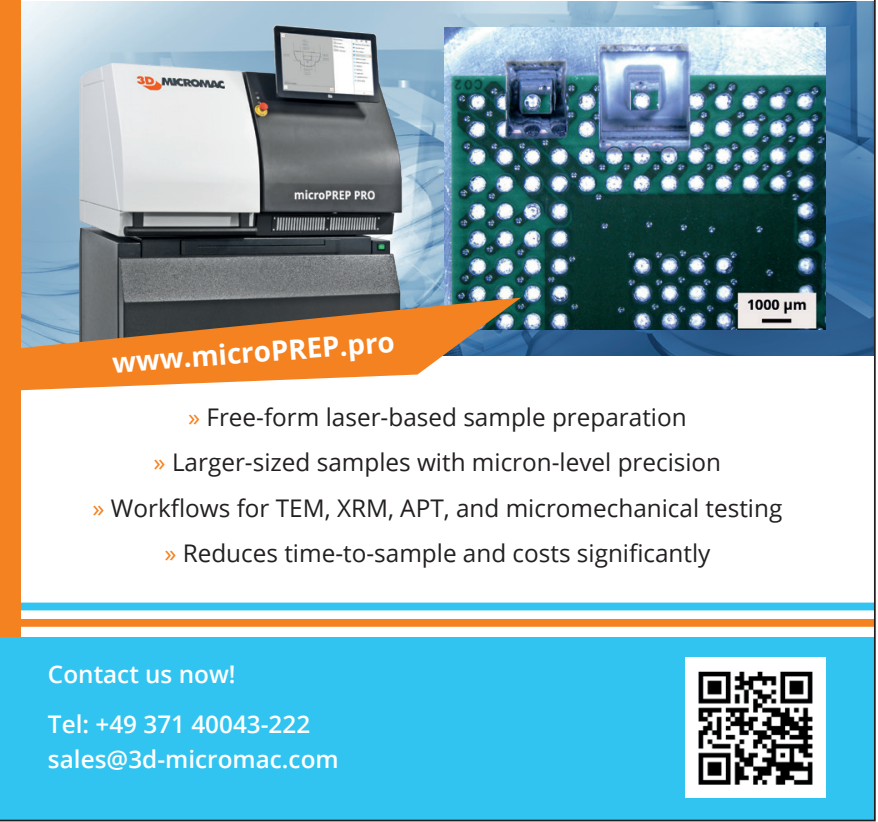

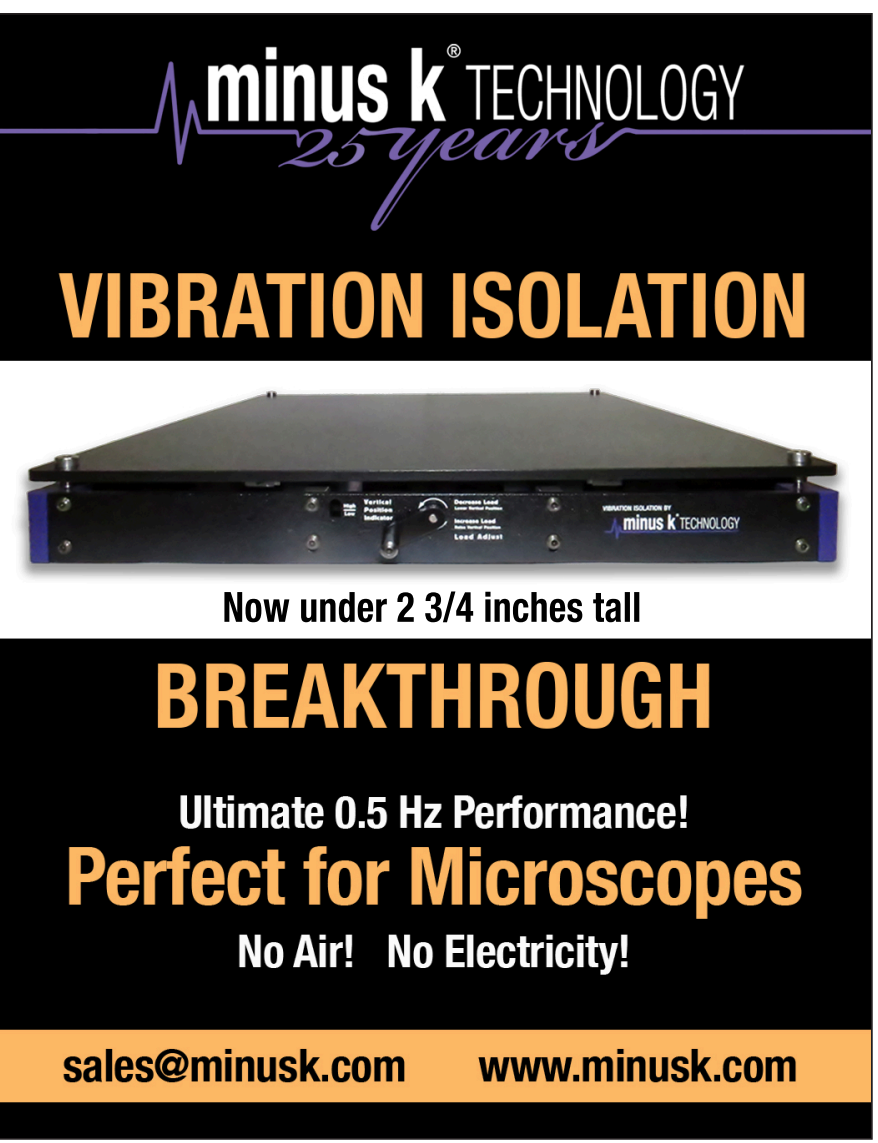

\section{SEM Scintillators \& Light Guides} Light Guide Recoating Services too!

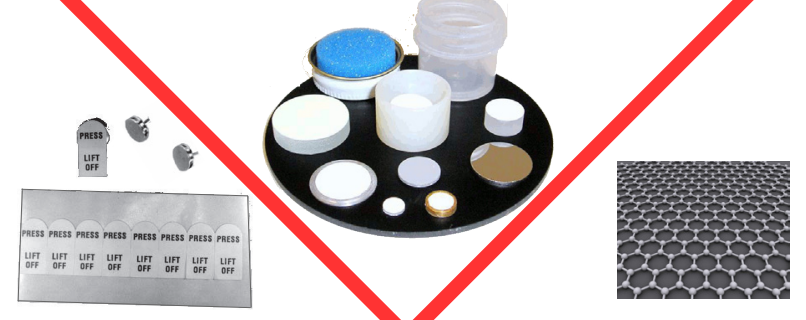

Conductive Adhesives, Introducing GRAPHENE Coatings \& Tabs! The New Carbon!

Brush or Spray the same product!

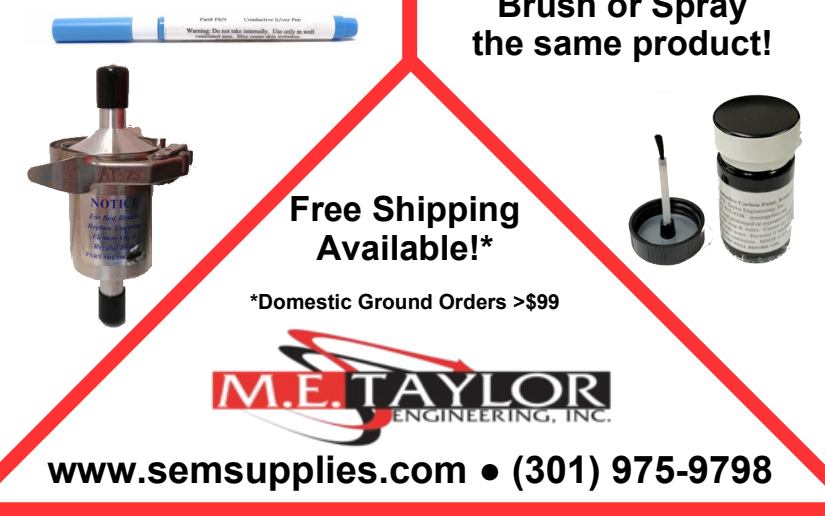

